\title{
EL DERECHO A LA INFORMACIÓN DE LAS ADR DE CONSUMO TRAS EL CASO C-380/19
}

\section{THE RIGHT TO INFORMATION FOR CONSUMER ADRS FOLLOWING CASE C-380/19}

\author{
María José Catalán Chamorro \\ Profesora. Ayudante Doctor de Derecho Procesal \\ Universidad de Córdoba
}

Recibido: 12.12.2020 / Aceptado: 12.01.2021

DOI: https://doi.org/10.20318/cdt.2021.5992

\begin{abstract}
Resumen: Los derechos de los consumidores han estado históricamente protegidos por la Unión Europea. Esto ha afectado fundamentalmente a los derechos sustantivos, pero poco se ha avanzado en el reconocimiento de derechos procesales que permitan a los consumidores obtener una tutela efectiva de sus pretensiones. Por ello, fue importante la entrada en vigor de la Directiva 2013/11 sobre resolución alternativa de litigios en materia de consumo. En este sentido, el TJUE y sus pronunciamientos proconsumidor mejoran la calidad de las transposiciones de las normas a las legislaciones nacionales y sus interpretaciones.
\end{abstract}

Palabras clave: ADR, Derecho de información al consumidor, Directiva 2013/11.

Abstract: Consumer rights have historically been protected by the European Union. This has mainly affected substantive rights, but there has been little progress in the recognition of procedural rights to enable consumers to obtain effective protection of their claims. The entry into force of Directive 2013/11 on alternative dispute resolution in consumer matters was therefore important. In this respect, the ECJ and its pro-consumer pronouncements improve the quality of the transposition of the rules into national legislation and their interpretation.

Keywords: ADR, Consumer Information Rights, Directive 2013/11.

Sumario: I. Introducción. II. El derecho a la información de los consumidores, III. El derecho de información de recurrir a un mecanismo de reclamación no judicial, IV. Los ADR de consumo en la Unión Europea, 1. ADR de consumo ¿Voluntarios?, 2. El derecho del consumidor a la información sobre el ADR. V. Conclusiones.

\section{Introducción}

1. El TJUE se ha posicionado una vez más como protector y garante de los derechos de los consumidores a la luz de la STJUE Bundesverband der Verbraucherzentralen und Verbraucherverbände-Verbraucherzentrale Bundesverband eV y Deutsche Apotheker-und Ärztebank e $G^{l}$. Este asunto se funda en una petición de decisión prejudicial planteada por el Tribunal Superior Regional de lo Civil y Penal de Düsseldorf, Alemania (Oberlandesgericht Düsseldorf) fruto de la demanda planteada

${ }^{1}$ STJUE 25 junio 2020, asunto C-380/19, (EU:C:2020:498). 
por la Federación de Organizaciones y Asociaciones de Consumidores -Federación de Organizaciones de Consumidores, Alemania- (Bundesverband der Verbraucherzentralen und Verbraucherverbände Verbraucherzentrale Bundesverband eV) contra un banco cooperativo del sector de la salud con sede en Düsseldorf -Deutsche Apotheker- und Ärztebank e $G$-, (en adelante, banco) por una presunta violación del deber de información a sus consumidores sobre la entidad ADR a la que estaba adherido para resolver los conflictos derivados de su actividad comercial en el ámbito financiero.

2. La duda que plantea el Tribunal remitente se ciñe a cuestionar el lugar y el modo en el que el banco debe ofrecer la información referente a la entidad de mediación en consumo a la que este estaba vinculado para la resolución de los conflictos con sus clientes. Concretamente se plantea si el hecho de publicar esta información obligatoria en su sitio web y no incluir dicha información en las condiciones generales de los contratos que utiliza con sus clientes es suficiente para cumplir con la normativa europea de información al consumidor. Así mismo, se plantea si el hecho de entregar dicha información en un documento separado en el momento de la firma del contrato cumpliría con la obligación establecida en el artículo 13 de la Directiva 2013/11.

3. Este trabajo pretende dar luz al desconocido y complejo mundo de la información precontractual obligatoria y pone en valor la importancia de una información adecuada sobre los métodos ADR disponibles para reclamar a cualquier entidad o comercio, ya que en muchas ocasiones se sitúa como única vía para el acceso a la justicia -alternativa- de los consumidores.

\section{El derecho a la información de los consumidores}

4. El derecho a la información de los consumidores es un derecho básico ${ }^{2}$ y consolidado. Podemos afirmar que las características de los contratos, sobre bienes o servicios adquiridos por los consumidores, deben estar perfectamente detalladas y pormenorizadas en los mismos. No obstante, el detalle de esta información contractual, así como la comprensibilidad de su lenguaje por parte de los consumidores medios y vulnerables sigue generando multitud de cuestiones prejudiciales en el TJUE. Ejemplo de ello son las cuestiones recientemente planteadas por los asuntos C-336/20 3 o el C-187/20 ${ }^{4}$, pendientes actualmente ante el Tribunal de Justicia, y que versan sobre la información que deben contener los contratos de crédito al consumo a la luz de la Directiva 2008/48/CE del Parlamento Europeo y del Consejo, de 23 de abril de 2008, relativa a los contratos de crédito al consumo y por la que se deroga la Directiva 87/102/CEE del Consejo5 ${ }^{5}$. Estas cuestiones son fruto de la complejidad de las cláusulas impuestas en los contratos de productos financieros, créditos al consumo o hipotecas. Y es que en la actualidad los consumidores deben hacer frente a técnicas mucho más agresivas en el tráfico comercial. Cuestión que se agudiza en los contratos celebrados a través del medio online o a distancia, a pesar del refuerzo en la legislación que tenemos ante estos retos ${ }^{6}$.

5. Este deber de información es básico para la prestación de un consentimiento libremente formado, exento de vicios y de buena fe. De este modo, el comerciante se sitúa como último responsable

\footnotetext{
${ }^{2}$ Así reza en el artículo 8 del TRLGDCU (antiguo artículo segundo de la Ley 26/1984, de 19 de julio, General para la Defensa de los Consumidores y Usuarios) sobre los derechos básicos de los consumidores y usuarios en su apartado d) La información correcta sobre los diferentes bienes o servicios y la educación y divulgación para facilitar el conocimiento sobre su adecuado uso, consumo o disfrute.

${ }^{3}$ Asunto Bank 11 für Privatkunden und Handel GmbH.

${ }^{4}$ Asunto BMW Bank and Volkswagen Bank.

${ }^{5}$ DOUE núm. 133, de 22 de mayo de 2008.

${ }^{6}$ Como por ejemplo la Directiva 2011/83/UE sobre los derechos de los consumidores o la Directiva (UE) 2019/2161 por la que se modifica la Directiva 93/13/CEE y las Directivas 98/6/CE, 2005/29/CE y 2011/83/UE en lo que atañe a la mejora de la aplicación y la modernización de las normas de protección de los consumidores de la Unión Europea. Ver más en: https:// eur-lex.europa.eu/legal-content/ES/TXT/?uri=LEGISSUM\%3A0904_4, visitado el día 6 de noviembre de 2020.
} 
de la comprensión por parte del consumidor de toda la información precontractual, especialmente en los casos donde, de haber conocido el consumidor toda la información su voluntad a la hora de consentir el contrato podría haber sido diferente. Así, el comerciante tiene una doble obligación, por un lado, abstenerse de dar información errónea y por el otro, transmitir toda la información exigible?

6. Dentro de esta información exigible, se nos plantean además dos escenarios donde el consumidor debe ser informado de los términos y condiciones del contrato. Por un lado, el escenario contractual, es decir, lo contenido e incluido en el contrato con la suficiente claridad y, por otro lado, en cuanto a la información obligatoria que legalmente es exigible. En este último escenario, es decir en la información obligatoria en determinados contratos de determinados sectores, hemos avanzado mucho en el ámbito europeo en los últimos años. Ejemplo de ello son los riesgos susceptibles de provenir de una utilización previsible, en función de la naturaleza, características, duración, garantías, derecho de desistimiento y las personas a las que vaya dirigido el bien o servicio de manera clara y comprensible.

7. De esta manera, la extensión de esta información no queda circunscrita al ámbito del contrato, sino que se extiende al etiquetado, a las ofertas o a la información precontractual que permite a los consumidores ejercer eficazmente sus derechos. Concretamente en este trabajo pondremos el foco de atención en el modo de proporcionar la información, que permite a los consumidores ejercer sus derechos a través de la resolución alternativa de conflictos.

8. El derecho a la información podemos dividirlo en dos fases del contrato, por un lado, la fase precontractual que se encuentra especialmente regulada en la contratación a distancia y, por otro lado, la información contractual donde podemos advertir dentro de las condiciones generales de la contratación diversas cláusulas abusivas.

9. Así las cosas, fijado como uno de los últimos derechos reconocidos a los consumidores, gracias al impulso de la Unión Europea, la información precontractual es básica para la defensa de sus derechos, así como para el ejercicio del acceso a la justicia, ya sea a través de los tribunales ordinarios o a través de los métodos ADR -de resolución alternativa de conflictos-. Es importante recordar, que no cabe la renuncia de estos derechos por ser consideradas cláusulas abusivas aquellas que limitan o privan al consumidor y usuario de los derechos reconocidos por normas dispositivas o imperativas, recogido así por el artículo 3 -y anexo- de la Directiva 93/13/CEE del Consejo, de 5 de abril de 1993, sobre las cláusulas abusivas en los contratos celebrados con consumidores ${ }^{8}$ y su transposición nacional en nuestro artículo 86 del Real Decreto Legislativo 1/2007, de 16 de noviembre, por el que se aprueba el texto refundido de la Ley General para la Defensa de los Consumidores y Usuarios y otras leyes complementarias. 9 es que tal y como afirma LoIS CABALLÉ "un consumidor informado es un consumidor protegido"10. Por ello, debemos poner en valor lo importantes que han sido los diferentes pronunciamientos del Tribunal de Justicia de la Unión Europea ${ }^{11}$ respecto de la necesidad de transparencia sobre las cláusulas que conforman costes y gastos para el consumidor, especialmente en los últimos tiempos ante el maltratado consumidor financiero. De este modo, resulta una cuestión esencial la determinación de cuál debe ser el nivel de información necesaria proporcionada por el profesional al cliente-consumidor y el modo de

\footnotetext{
${ }^{7}$ M.A. ZuRilla Cariñana, "El Derecho Básico a la Información de los consumidores y usuarios: Luces y sombras de la legislación española”, en E. Coelho De Azevedo Bussinguer, C. Luiz Strapazzon, y M.A. Zurilla Cariñana (Coord.), Derechos básicos de los ciudadanos. Efectividad y grado de cumplimiento en los sistemas legales, Ed. Universidad de Castilla-La Mancha, pp. 100-101.

${ }^{8}$ DOCE núm. 95, de 21 de abril de 1993.

${ }^{9}$ BOE núm. 287, de 30 de noviembre de 2007.

${ }^{10}$ A. Lois Caballé, "Venta a distancia y contratos celebrados fuera del establecimiento", en P. Pajín Echevarría (Coord)., GPS de Consumo, Tirant Lo Blanch, Valencia, 2017, pp. 295-297.

${ }^{11}$ Como la STJUE 21 de diciembre de 2016 Asuntos acumulados C-154/15, C-307/15 y C-308/15, donde se establece que el control de transparencia material se extiende a todas las cláusulas contractuales y alcanza también a la información precontractual que recibe el cliente consumidor.
} 
facilitación de esta ${ }^{12}$. Prácticamente esta cuestión es la que se plantea en el reciente pronunciamiento del TJUE -que analizamos al final del trabajo- respecto a la información obligatoria contractual sobre la accesibilidad de la información relativa a los medios ADR a los que está sometida la empresa -de manera voluntaria o legalmente obligada- en virtud de la necesidad de información establecida para los comerciantes en el artículo 13 de la Directiva 2013/11 del Parlamento Europeo y del Consejo, de 21 de mayo de 2013, relativa a la resolución alternativa de litigios en materia de consumo y por la que se modifica el Reglamento (CE) no 2006/2004 y la Directiva 2009/22/CE ${ }^{13}$.

10. En el presente trabajo nos centraremos en la importancia de la información sobre la posibilidad de recurrir a un mecanismo no judicial de reclamación y posibles recursos a los que pueda estar sujeto el comerciante, así como el modo de tener acceso a los mismos ${ }^{14}$. Esta obligación de informar se estableció en un primer momento como requisito de información necesario en la fase precontractual de los contratos celebrados a distancia y los contratos celebrados fuera del establecimiento comercial a través de la Directiva 2011/83/UE ${ }^{15}$. Es decir, esta información debe prestarse al consumidor antes de que el consumidor quede vinculado por cualquier contrato a distancia o celebrado fuera del establecimiento, donde el comerciante le debe facilitar de forma clara y comprensible esta información. Además, el comerciante está obligado a proporcionar otras informaciones como las características principales de los bienes o servicios, la identidad del comerciante; la dirección geográfica del establecimiento y los datos del mismo; el precio total; el coste de la utilización de las comunicaciones; los procedimientos de pago y entrega; la forma de ejecución del derecho de desistimiento; los costes de devolución; la garantía; el servicio posventa, informar si está adherido a algún código de conducta; la duración del contrato o su prórroga automática; la duración mínima de las obligaciones; las condiciones de los depósitos o garantías financieras de las que deba hacerse cargo el consumidor, así como los contenidos digitales disponibles y su interoperabilidad.

11. La etapa precontractual en el ámbito del consumo ha sido protegida desde las diferentes directivas europeas, aunque no se ha legislado de manera homogénea para todas las tipologías de contratos. De este modo, podemos ver cómo en la Directiva 2014/17/Unión Europea de 4 de febrero de 2014, sobre los contratos de crédito celebrados con los consumidores para bienes inmuebles de uso residencial ${ }^{16}$, se le da especial importancia a la información precontractual ofrecida a los clientes hipotecarios, que deberá ofrecérsele de manera personalizada y pormenorizada. Incluso en estos casos se ha articulado la llamada FEIN -Ficha Europea de Información Normalizada-, que detalla los datos oficiales que las entidades financieras tienen que entregar a los clientes que vayan a solicitar la concesión de un préstamo hipotecario con ellas, es decir, antes de la formalización del contrato. Así se delimitan las cuestiones más importantes de la hipoteca que obligatoriamente deben ser facilitadas en un documento, de fácil comprensión, a los futuros prestatarios donde se incluyen las cuestiones respecto a la reclamación extrajudicial de conflictos que pudiese darse con la entidad ${ }^{17}$. También se protege especialmente el

${ }^{12}$ C.C. Castillo Martínez, La nulidad de la cláusula de gastos en los préstamos hipotecarios con consumidores, Tirant Lo Blanch, Valencia, pp. $34-25$.

${ }^{13}$ DOUE núm. 165, de 18 de junio de 2013.

${ }^{14}$ Artículo 6.1.f) de la Directiva 2011/83/Unión Europea.

${ }^{15}$ Ver más en el Documento De Orientación De La DG Justicia relativo a la Directiva 2011/83/UE del Parlamento Europeo y del Consejo, de 25 de octubre de 2011, sobre los derechos de los consumidores, por la que se modifican la Directiva 93/13/CEE del Consejo y la Directiva 1999/44/CE del Parlamento Europeo y del Consejo y se derogan la Directiva 85/577/CEE del Consejo y la Directiva 97/7/CE del Parlamento Europeo y del Consejo de junio de 2014 y MENDOZA LosAnA, A.I., "Información precontractual en la directiva 2011/83 novedades, exigencias y carencias", Revista Cesco de Derecho de Consumo, №1/2012, pp. 22-28.

${ }^{16}$ y por la que se modifican las Directivas 2008/48/CE y 2013/36/UE y el Reglamento (UE) n ${ }^{\circ} 1093 / 2010$. DOUE núm. 305 , de 24 de octubre de 2014.

${ }^{17}$ Según figura en el anexo de la citada Directiva, en la FEIN debe aparecer la siguiente información: Si tiene una reclamación, diríjase a [insértense los datos del punto de contacto interno y la fuente de información sobre el procedimiento]. (Si ha lugar) Plazo máximo para la tramitación de la reclamación: [período de tiempo]. (Si ha lugar) [Si no resolvemos internamente la reclamación a su entera satisfacción,] puede usted dirigirse a: [insértese el nombre del organismo externo que se ocupe de las reclamaciones y recursos extrajudiciales] (si ha lugar) o ponerse en contacto con la red FIN-NET para obtener las señas del organismo equivalente en su país. 
derecho de información precontractual en los contratos a distancia ${ }^{18}$ tal y como comentábamos supra o en los contratos de aprovechamiento por turno de bienes inmuebles de uso turístico ${ }^{19}$.

12. De esta manera, la falta de transparencia o de suficiente información precontractual puede llevar al tribunal a dictar el carácter abusivo de una condición general que regule un elemento esencial del contrato por falta de transparencia. Ésta será apreciada cuando falte la información adecuada por parte del comerciante sobre la existencia y trascendencia de una cláusula contractual perjudicial para el consumidor. Por ello, la falta de transparencia no deriva únicamente de una oscuridad interna, (gramatical o documental) sino de la insuficiencia de la información, dada la trascendencia de tal cláusula en el entramado y desarrollo jurídico y económico del negocio. Por ello, las cláusulas generales exigen al comerciante un plus de información sobre elementos esenciales del contrato, que permitan al consumidor poder adoptar su decisión con pleno conocimiento de causa, sin necesidad de un examen exhaustivo y pormenorizado del contrato ${ }^{20}$. Tanto es así que el Tribunal Supremo ha determinado en la STS 25/2018 de 17 enero $^{21}$ que la información precontractual es la que permite realmente al consumidor comparar ofertas y adoptar la decisión de contratar. En esta misma sentencia se cita más jurisprudencia del TJUE en la que se ha abordado la información del consumidor en contratos de crédito ${ }^{22}$. En ella, el magistrado Vela entiende a tenor de estas resoluciones, que no solo es necesario que las cláusulas estén redactadas de forma clara y comprensible, sino también que el adherente pueda tener un conocimiento real de las mismas, de forma que un consumidor informado pueda prever, sobre la base de criterios precisos y comprensibles, la carga jurídica y económica del contrato.

13. En definitiva, el derecho de información al consumidor ha conquistado una posición preeminente en la regulación comunitaria sobre todo tras la transposición de la Directiva 2011/83/UE, no confinada o reducida a la perspectiva precontractual o contractual, sino que se ha incluido de una manera transversal y especifica atendiendo a las necesidades de los consumidores. En cierta medida, ahora se confía en una perspectiva global e integradora del derecho a la información como derecho de los consumidores y usuarios frente al acto de consumo en general y de cuya efectividad han de velar los poderes públicos, quienes asegurarán que éstos dispongan de la información precisa para el eficaz ejercicio de sus derechos y velarán para que se les preste la información comprensible sobre el adecuado uso y consumo de los bienes y servicios puestos a su disposición en el mercado tal y como cita el artículo 17 del TRLGDCU ${ }^{23}$.

\section{El derecho de información de recurrir a un mecanismo de reclamación no judicial}

14. Los métodos o procedimientos de resolución alternativa de conflictos suponen, una vía de acceso a la justicia para la población en general y concretamente más para los consumidores. Y es que esta justicia alternativa cobra aún más sentido cuando la aplicamos en el ámbito de consumo debido a la escasa cuantía de las reclamaciones y a la sencillez en el trámite de estos mecanismos.

\footnotetext{
${ }^{18}$ Ver más en: J.R. García Vicente, "Los Contratos Celebrados A Distancia”, en R. Bercovitz Rodríguez-Cano (Dir.), N.

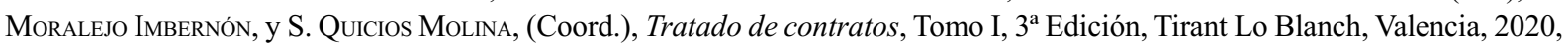
pp. 1934-1935.

${ }^{19}$ Ver más en: L. Costas Rodal, "Contratos de cesión temporal de uso y disfrute”, en R. Bercovitz Rodríguez-Cano (Dir.),

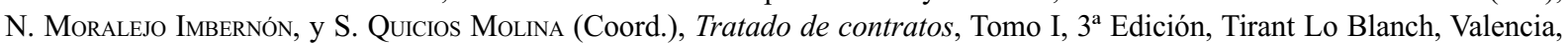
2020, pp. 3464-3467.

${ }^{20}$ G., Caruana Font De Mora, "La contratación por condiciones no negociadas con el consumidor", en P. Pajín EcheVArRía(Coord.), GPS de Consumo, Tirant Lo Blanch, Valencia, 2020, p. 573.

${ }^{21}$ B.D. Aranzadi RJ $2018 \backslash 34$.

${ }^{22}$ Las citadas son la STJUE 21 de marzo de 2013 (TJCE 2013, 93), asunto C-92/11, caso RWE Vertrieb; STJUE 30 de abril de 2014 (TJCE 2014, 105), asunto C-26/13, caso Kásler y Káslerne Rába; 26 de febrero de 2015 (TJCE 2015, 93), asunto C-143/13, caso Matei y Matei y STJUE 23 de abril de 2015 (TJCE 2015, 179), asunto C-96/14, caso Van Hove.

${ }^{23}$ N. Álvarez Lata, "Información al consumidor, prácticas comerciales y publicidad”, en M. Busto Lago (Coord.), Reclamaciones de consumo. Materiales para la construcción de un Tratado de Derecho de consumo, $4^{\mathrm{a}}$ ed., Thomson Reuters, enero 2020, RB-2.1.
} 
15. Estos mecanismos de resolución alternativa de litigios (en adelante, ADR) -Alternative Dispute Resolution- se caracterizan por su fácil accesibilidad, su ágil tramitación y su bajo coste, si lo comparamos con los sistemas de justicia ordinarios dirigidos por los jueces y tribunales. Cuando hablamos de ADR generalmente son sistemas basados en la voluntariedad de las partes y esto, trasladado al ámbito del consumo donde nos encontramos, significa que tanto el consumidor como el comerciante deben voluntariamente someterse a un procedimiento ADR para solventar el conflicto. En este punto encontramos diversas dificultades tanto por parte del comerciante, como por parte del consumidor. Del lado del consumidor debemos poner de relieve el desconocimiento general de la ciudadanía sobre la existencia de estas vías de reclamación. Especialmente, en países de poca tradición de justicia alternativa donde podemos incluir a España. Es entonces cuando nos encontramos con pocas entidades dedicadas al ADR, fundamentalmente debido al desconocimiento sobre los mismos que tiene la población mayoritaria. En muchas ocasiones esto se debe a la poca implicación que tienen las administraciones públicas en su impulso, que deberían informar y formar a la ciudadanía en estas vías, tanto o más de lo que se hace sobre la vía judicial, incluso desde la educación secundaria obligatoria.

16. Es por ello por lo que aún nos queda mucho por avanzar en el ámbito de los ADR de consumo, que pueden adoptar diversas formas, desde la negociación inicial del empresario con el consumidor, pasando por una mediación o intermediación, muy usuales en nuestro país en el ámbito hipotecario, una conciliación o un arbitraje. El arbitraje es el método más utilizado en nuestro país para la resolución alternativa de litigios debido a nuestra apuesta por el institucionalizado Sistema Arbitral de Consumo, un sistema público y gratuito tanto para el consumidor como para el empresario, pero que cada vez es menos utilizado debido a la falta de información de la población. Todo ello, sin dejar atrás el sistema ombudsman, no utilizado en nuestro país, pero con una fuerte tradición histórica en los países escandinavos e Inglaterra.

17. Con esta motivación la Comisión Europea y el Parlamento Europeo impulsaron especialmente para las adquisiciones de bienes a distancia o fuera del establecimiento comercial la obligatoriedad de informar al consumidor sobre la posibilidad de recurrir a un mecanismo no judicial de reclamación y recurso al que esté sujeto el comerciante y los métodos para tener acceso al mismo a través del artículo 6.1.t) de la Directiva 2011/83/Unión Europea, anteriormente comentada. Sin embargo, esta obligatoriedad no quedó ahí y se impuso para el resto de contratos de compraventa o de prestación de servicios celebrados entre un comerciante establecido en la Unión y un consumidor residente en la Unión, solo dos años más tarde a través de la Directiva 2013/11 del Parlamento Europeo y del Consejo, de 21 de mayo de 2013, relativa a la resolución alternativa de litigios en materia de consumo y por la que se modifica el Reglamento (CE) n 2006/2004 y la Directiva 2009/22/CE (en adelante, Directiva 2013/11).

18. En la exposición de motivos de esta Directiva se estableció la necesidad de que los consumidores, cuando les surja un conflicto con un comerciante de la Unión Europea, puedan identificar rápidamente qué entidades de resolución alternativa son competentes para tratar su reclamación y saber si el comerciante afectado participará o no en el procedimiento sometido a una entidad de resolución alternativa. Por ello, constriñe a los comerciantes a que se comprometan a recurrir a tales entidades para la resolución de litigios con los consumidores, así como a informar a los consumidores sobre, al menos, la dirección del sitio web de la entidad o entidades de resolución alternativa que les amparen. Además, dicha información se debe facilitar de forma clara, comprensible y fácilmente accesible en el sitio web del comerciante cuando exista y, en su caso, en las condiciones generales de los contratos de compraventa de mercancías o prestación de servicios entre el comerciante y los consumidores ${ }^{24}$.

\footnotetext{
${ }^{24}$ A. CuENCA García, "Los principios de transparencia, eficacia, equidad, libertad y legalidad en la Directiva 2013/11/UE del parlamento europeo y del consejo de 21 de mayo de 2013, relativa a la resolución alternativa de litigios en materia de consumo, y su incidencia en el sistema de arbitraje de consumo español", en G. PALAu Moreno (Ed.), Los nuevos instrumentos europeos en materia de conciliación, mediación y arbitraje de consumo su incidencia en España, Irlanda y el Reino Unido, Tirant Lo Blanch, Valencia, 2016, pp. 42-43.
} 
Así las cosas, los comerciantes deben incluir en sus sitios web, y en las condiciones generales del contrato de que se trate, cualquier información complementaria sobre sus procedimientos internos de tramitación de reclamaciones o sobre cualesquiera otros modos de entrar en contacto directo con ellos, con miras a la resolución de litigios con los consumidores sin remitirlos a una entidad de resolución alternativa.

Y para los casos en los que el litigio no pudiese resolverse de forma directa por el comerciante a través de una breve negociación, este deberá facilitar al consumidor, en papel o en cualquier otro soporte duradero, información sobre las entidades de resolución alternativa correspondientes y precisar si recurrirá a ellas. Concretamente, en este punto es donde se ha detenido el TJUE tras una cuestión prejudicial planteada por Bundesverband der Verbraucherzentralen und Verbraucherverbände -Verbraucherzentrale Bundesverband eV contra Deutsche Apotheker- und Ärztebank eG que posteriormente analizaremos.

19. Además, tal y como apunta la Directiva 2013/11, la obligación de los comerciantes de informar a los consumidores acerca de las entidades de resolución alternativa que amparan a dichos comerciantes debe entenderse sin perjuicio de la obligación de información a los consumidores acerca de los procedimientos de recurso extrajudicial establecidos en otros actos jurídicos de la Unión que deban aplicarse. Por lo tanto, podemos distinguir una doble información. Por un lado, la información acerca de las entidades ADR a las que el comerciante está sometido, y por otro la información sobre la existencia de mecanismos ADR en el ámbito de la Unión Europea como pueden ser la plataforma de ODR de consumo $^{25}$, la red Fin- $\mathrm{Net}^{26}$, Centros Europeos del Consumidor ${ }^{27}$ (CEC), entre otros.

20. Sin embargo, la Directiva 2013/11 no exige que la participación de los comerciantes en procedimientos de resolución alternativa sea obligatoria o que el resultado de dichos procedimientos sea vinculante para los comerciantes cuando un consumidor haya presentado una reclamación contra ellos. No obstante, la citada Directiva no contempla los casos donde existan normas nacionales que hagan obligatoria la participación de los comerciantes de determinados sectores en dichos procedimientos, ni la incentive, sancione o les obliga a aceptar su resultado. El único requisito que siempre va a exigir la normativa europea es que dichas normas no impidan a las partes ejercer su derecho a acceder al sistema judicial, tal como establece el artículo 47 de la Carta de los Derechos Fundamentales de la Unión Europea. Es decir, siempre que tanto comerciante como consumidor puedan acudir posteriormente a la vía judicial, en los casos en los que la vía extrajudicial no les sea satisfactoria.

Si bien, con el fin de garantizar que los consumidores tengan una vía de recurso y que no se vean obligados a renunciar a sus reclamaciones, esta Directiva anima a los comerciantes, en la medida de lo posible, a que participen en procedimientos de resolución alternativa de conflictos.

\section{Los ADR de consumo en la Unión Europea}

21. Llegados a este punto debemos situar a la Unión Europea como gran artífice e impulsora de los Alternative Dispute Resolution (ADR), o su traducción al español mecanismos de resolución alternativa de litigios en el ámbito del consumo en todo el espacio económico europeo ${ }^{28}$.

22. Es importante distinguir dos momentos esenciales en el desarrollo e impulso de los ADR de consumo por parte de la Unión Europea. En un primer momento, sobre la década de los ochenta y

\footnotetext{
${ }^{25}$ Disponible en: https://ec.europa.eu/consumers/odr/main/?event=main.adr.show2, visitada el día 20 de noviembre de 2020.

${ }^{26}$ Disponible en: https://ec.europa.eu/info/business-economy-euro/banking-and-finance/consumer-finance-and-payments/ retail-financial-services/financial-dispute-resolution-network-fin-net_es, visitada el día 20 de noviembre de 2020.

${ }^{27}$ Versión española disponible en: https://cec.consumo.gob.es/CEC/web/home/index.htm, visitada el día 20 de noviembre de 2020.

${ }^{28}$ Podemos situar como primer hito en esta materia el Coloquio sobre los medios judiciales y cuasi-judiciales para la protección de los consumidores, organizado por la Comisión Europea en 1975.
} 
noventa, de la mano del surgimiento del movimiento consumerista ${ }^{29}$, con la motivación de facilitar el acceso a los consumidores a una justicia sencilla y flexible para que pudiesen ejercerla de manera efectiva, sin trabas judiciales o quotas litis que disuadiesen las reclamaciones de consumo ${ }^{30}$. Y en un segundo momento, desde inicios del siglo XXI, donde distinguimos un punto de inflexión en la motivación para el impulso de los ADR de consumo, a través de la creación del espacio económico de libre comercio donde los ADR de consumo se utilizarían fundamentalmente para fomentar la confianza de los consumidores ciudadanos europeos en los comerciantes sitos en cualquier país de la Unión Europea, es decir aumentar la certidumbre de los consumidores ${ }^{31}$ para que realicen compras transfronterizas dentro del mercado único ${ }^{32}$. Actualmente vivimos inmersos en este cambio de tendencia, donde lo que la Unión Europea pretende es animar e incitar al comercio tanto físico como presencial de la ciudadanía europea, asistiéndolos de una suerte de justicia alternativa para los casos en los que los consumidores tengan algún tipo de reclamación o problema con los comerciantes europeos.

23. Así las cosas, en virtud de estas motivaciones entran en vigor los dos instrumentos más importantes en materia de tutela extrajudicial de consumo de la Unión Europea hasta el momento como son la Directiva 2013/11/UE, del Parlamento Europeo y del Consejo, de 21 de mayo de 2013, relativa a la resolución alternativa de litigios en materia de consumo y el Reglamento 524/2013 sobre resolución alternativa de conflictos en línea ${ }^{33}$. Estos instrumentos vienen a reequilibrar el desfase entre el reconocimiento de derechos sustantivos en materia de consumo desde los años noventa ${ }^{34}$ con la falta de derechos procesales para ejercer estos derechos de los consumidores. Aunque tal y como nos está mostrando la experiencia, estos mecanismos no son tan efectivos como se muestran, ya que la legislación se quedó corta a la hora de regular, ejemplo de ello es la plataforma ODR de la Unión Europea creada por la Comisión Europea en febrero de $2015^{35}$.

${ }^{29}$ G., Palao Moreno, "La protección de los consumidores en el ámbito comunitario europeo", en M.J. ReYes LóPez (Coord.), Derecho de Consumo, Tirant lo Blanch, Valencia, 2002, pp. 47-48. Y, L. M. Miranda Serrano y M. Paniagua ZureRA, "La Protección de los consumidores y usuarios y la irrupción del Derecho de los consumidores", en L. M. Miranda SERRANO y J. Pagador López (Coord.), Derecho (Privado) de los consumidores, Ed. Marcial Pons, Madrid, 2012, p. 37.

${ }^{30}$ Ejemplo de ello fue la creación del Libro Verde sobre el acceso de los consumidores a la justicia y solución de litigios de consumo en el mercado único de 1993, donde se establecieron los cimientos del sistema que hoy disfrutamos. (COM (93) 576 final, de 16 de noviembre de 1993).

${ }^{31}$ Donde ya se avanzaba a mecanismos de defensa de los consumidores más complejos y avanzados como fueron los primeros pasos de la defensa colectiva de los consumidores a través de la Directiva 98/27EC sobre Reclamaciones Colectivas De Consumo, posteriormente modificada del Libro Verde sobre el recurso colectivo de los consumidores (COM (2008) 0794 final) o de la acción de cesación a través de la Recomendación de la Comisión de 11 de junio de 2013, sobre los principios comunes aplicables a los mecanismos de recurso colectivo de cesación o de indemnización en los Estados miembros en caso de violación de los derechos reconocidos por el Derecho de la Unión. Entre otros, que no solo protegían los derechos de los consumidores sino también de los comerciantes ante la competencia desleal como el Libro Blanco de Acciones de daños y perjuicios por incumplimiento de las normas comunitarias de defensa de la competencia (COM (2008) 165 final).

${ }^{32}$ Véase el Dictamen del Comité Económico y Social Europeo sobre la «Comunicación de la Comisión al Parlamento Europeo, al Consejo, al Comité Económico y Social Europeo y al Comité de las Regiones: Una Agenda del Consumidor Europeo para impulsar la confianza y el crecimiento» [COM (2012) 225 final]

${ }^{33}$ DOUE núm. 165, de 18 de junio de 2013.

${ }^{34}$ Ejemplo de ello son, por ejemplo: la Directiva 90/314/CEE del Consejo, de 13 de junio de 1990, relativa a los viajes combinados, las vacaciones combinadas y los circuitos combinados (DO L 158 de 23. 6. 1990, p. 59); la Directiva 92/28/CEE del Consejo, de 31 de marzo de 1992, relativa a la publicidad de los medicamentos para uso humano (DO L 113 de 30. 4. 1992, p. 13); la Directiva 93/13/CEE del Consejo, de 5 de abril de 1993, sobre las cláusulas abusivas en los contratos celebrados con consumidores (DO L 95 de 21. 4. 1993, p. 29); la Directiva 94/47/CE del Parlamento Europeo y del Consejo, de 26 de octubre de 1994, relativa a la protección de los adquirentes en lo relativo a determinados aspectos de los contratos de adquisición de un derecho de utilización de inmuebles en régimen de tiempo compartido (DO L 280 de 29. 10. 1994, p. 83); la Directiva 97/7/ CE del Parlamento Europeo y del Consejo, de 20 de mayo de 1997, relativa a la protección de los consumidores en materia de contratos a distancia (DO L 144 de 4. 6. 1997, p. 19); la Directiva 98/27/CE del Parlamento Europeo y del Consejo de 19 de mayo de 1998 relativa a las acciones de cesación en materia de protección de los intereses de los consumidores

${ }^{35}$ Ver mas sobre esta cuestión en: Informe de la Comisión al Parlamento Europeo, al Consejo y al Comité Económico y Social Europeo sobre la aplicación de la Directiva 2013/11/UE del Parlamento Europeo y del Consejo, relativa a la resolución alternativa de litigios en materia de consumo, y del Reglamento (UE) n. ${ }^{\circ}$ 524/2013 del Parlamento Europeo y del Consejo, sobre resolución de litigios en línea en materia de consumo, Bruselas, 25 de septiembre de 2019, COMISIÓN (2019) 425 final. 


\section{ADR de consumo ¿Voluntarios?}

24. Es por todos conocido que una de las características esenciales de los ADR es el sometimiento voluntario por las partes a esta serie de métodos. Al contrario de lo que ocurre con los procesos judiciales, donde una de las contrapartes se ve obligada a someterse a una decisión judicial, aún cuando esta reniegue o no quiera someterse al mismo. Podemos decir que la característica más importante de los métodos ADR es la libertad de las partes para someterse voluntariamente a cualquier ADR, desde la negociación, la conciliación, la mediación o el arbitraje, incluso en los llamados ADR híbridos como son las fórmulas med-arb o med-con, entre otras ${ }^{36}$. Sin embargo, esta voluntariedad podría eludirse de manera excepcional por motivos de prevalencia de los intereses públicos ${ }^{37}$.

De este modo, en virtud de estos intereses públicos, de los consumidores en general y que imperan sobre los intereses puramente privados de los comerciantes, se ha podido eliminar este requisito sine qua non que suponía la voluntariedad de ambas partes para someterse a este tipo de procedimientos como veremos más adelante.

25. En la primera etapa de promoción de los ADR de consumo en la Unión Europea, entre las décadas de los ochenta y noventa, la adhesión a este tipo de instrumentos se planteaba como puramente voluntaria para las partes, a pesar del desequilibrio de las fuerzas entre los comerciantes y los consumidores.

Así las cosas, el legislador europeo pronto empezó a darse cuenta de que, aunque la utilización de los ADR de consumo suponía un símbolo de confianza y marketing para el comerciante y que esto haría que los consumidores apostasen por esas empresas para realizar sus compras, los ADR y su voluntariedad hacía que muy pocos comerciantes eligiesen a estas entidades para la resolución de conflictos ${ }^{38}$. Sobre todo, en países donde la tradición histórica o la idiosincrasia en los ADR de consumo era prácticamente nula o inexistente.

26. Llegados a este punto la Unión Europea podría haber optado por un camino legislativo que impulsase los ADR de consumo a través de incentivos fiscales o sellos de confianza europeos que permitiese a los comerciantes conocer los beneficios del uso de los $\mathrm{ADR}^{39}$. Es decir, aunque estos se adhiriesen por puro interés fiscal o para mejorar o posicionar su imagen comercial, pudiesen entender, a través de su experiencia propia, de la importancia y los beneficios del uso de este tipo de mecanismos para resolver sus conflictos ${ }^{40}$.

En cambio, la Unión Europea decidió optar por la desnaturalización de la voluntariedad ${ }^{41}$ para someterse a los ADR en algunos sectores con una alta litigiosidad. Principalmente se ha legislado en este sentido en sectores que prestan servicios esenciales para los consumidores. Así las cosas, los prestadores de ciertos servicios están obligados a someterse a una entidad ADR como el suministro de redes y servicios de comunicaciones electrónicas a los usuarios finales ${ }^{42}$, se reguló el proceso de reclamación

\footnotetext{
${ }^{36}$ A.E. Vilalta Nicuesa, Mediación y Arbitraje Electrónicos, Aranzadi, Cizur Menor (Navarra), 2013, p. 300.

${ }^{37}$ Ver más en profundidad este aspecto en: S. BARONA VILAR, Nociones y principios de las ADR, Tirant Lo Blanch, Valencia, 2018, p.39.

${ }^{38}$ C., Hodges, “Consumer Ombudsmen: Better Regulation and Dispute Resolution", ERA Forum, 15, (2014), pp. 595-596. https://doi.org/10.1007/s12027-014-0366-8

${ }^{39}$ Ver la repercusión positiva del uso de los ADR de consumo en el estudio publicado recientemente por C., WiLLIAMs, J., Gill, N. CreutzFeldt, N.Vivian, "Participation as a Framework for Analysing Consumers' Experiences of Alternative Dispute Resolution (ADR)", Journal Of Law And Society, Volume 47, Number 2, June 2020, pp. 271-97.

${ }^{40}$ P. CoRTÉs, The law of consumer redress in an evolving digital market, Cambridge University Press, Cambridge, 2017, pp. 207-208

${ }^{41}$ Ver más en profundidad este aspecto en: S. BARONa VILAR, Nociones y principios de las ADR, Tirant Lo Blanch, Valencia, 2018 , pp. 68 y 71.

${ }^{42}$ En virtud del artículo 34.1 de la Directiva 2002/22/CE del Parlamento Europeo y del Consejo de 7 de marzo de 2002 relativa al servicio universal y los derechos de los usuarios en relación con las redes y los servicios de comunicaciones electrónicas (Directiva de servicio universal), DOCE núm. 108, de 24 de abril de 2002.
} 
en servicios postales ${ }^{43} \mathrm{o}$ se designó por cada Estado miembro a una autoridad reguladora en el ámbito del mercado interior de la electricidad, quien en su calidad de organismo competente en la resolución de conflictos, emitirá una decisión en los dos meses siguientes a la recepción de cualquier reclamación de cualquier consumidor ${ }^{44}$. Sin embargo, no se han regulado todos los sectores esenciales, por lo que todavía queda mucho camino por avanzar en este sentido ${ }^{45}$.

27. Para otros sectores, que la Unión Europea ha entendido como "menos esenciales", simplemente se les ha animado o incitado a utilizar los ADR de consumo a través de las diferentes directivas, como es el sector del comercio electrónic ${ }^{46} \mathrm{o}$ los contratos de aprovechamiento por turno de bienes de uso turísti$\mathrm{co}^{47}$. Del mismo modo que ha ocurrido con los servicios financieros, donde tampoco se les obliga a adherirse a un ADR sino simplemente a informar al consumidor si están o no adheridos a una entidad $\mathrm{ADR}^{48}$.

28. No obstante, en algunas legislaciones nacionales también se obliga a determinados sectores a someterse a ADR para resolver los conflictos con sus consumidores. Por ejemplo, en la legislación alemana, las reclamaciones de la aviación comercial quedan sometidas obligatoriamente al $\mathrm{ADR}^{49}$, entre otros. Sin embargo, España no cuenta con ninguna legislación nacional que obligue al uso de los ADR a un sector concreto $^{50}$ y una vez más vamos a remolque de lo que la Unión Europea nos impulse en esta materia.

\section{El derecho del consumidor a la información sobre el ADR}

29. Así las cosas, la norma que más ha revolucionado la voluntariedad, la información al consumidor sobre los métodos ADR y la vinculación por parte de las empresas a este tipo de entidades de

\footnotetext{
${ }^{43}$ En virtud del artículo 13 de la Directiva 2008/6/CE del Parlamento Europeo y del Consejo, de 20 de febrero de 2008, por la que se modifica la Directiva 97/67/CE en relación con la plena realización del mercado interior de servicios postales comunitarios DOUE núm. 52, de 27 de febrero de 2008.

${ }^{44}$ En virtud de la Directiva 2009/72/CE del Parlamento Europeo y del Consejo de 13 de julio de 2009 sobre normas comunes para el mercado interior de la electricidad. Transpuesta al ordenamiento jurídico español a través del Real Decreto-ley $13 / 2012$, de 30 de marzo, por el que se transponen directivas en materia de mercados interiores de electricidad y gas y en materia de comunicaciones electrónicas, y por el que se adoptan medidas para la corrección de las desviaciones por desajustes entre los costes e ingresos de los sectores eléctrico y gasista.

${ }^{45}$ Por ejemplo, no es obligatorio el sometimiento a una entidad ADR para las entidades bancarias a pesar de la alta litigiosidad de este sector esencial para la ciudadanía y de la necesidad de acceder a esta vía alternativa para sus clientes. No obstante, en la actualidad la mayoría de las entidades se encuentran sometidas al defensor del cliente bancario, figura que es totalmente privada y depende económicamente, en la mayoría de los casos, de las entidades bancarias. Ver más en: A.I. BlanCo GARCíA, $L a$ tutela del cliente bancario y las ADR: la Institución del Ombudsman, Tirant Lo Blanch, Valencia, 2016, pp. 229-230

${ }^{46}$ A través de la Directiva 2000/31/CE del Parlamento Europeo y del Consejo, de 8 de junio de 2000, relativa a determinados aspectos jurídicos de los servicios de la sociedad de la información, en particular el comercio electrónico en el mercado interior (Directiva sobre el comercio electrónico). DOCE núm. 178, de 17 de julio de 2000. Concretamente en su artículo 17, que se afianzaría tras la puesta en marcha de la plataforma ODR creada por la Comisión Europea en virtud del Reglamento (UE) $\mathrm{n}^{\mathrm{o}}$ 524/2013 del Parlamento Europeo y del Consejo, de 21 de mayo de 2013, sobre resolución de litigios en línea en materia de consumo.

${ }^{47}$ A través de la Directiva 2008/122/CE del Parlamento Europeo y del Consejo, de 14 de enero de 2009, relativa a la protección de los consumidores con respecto a determinados aspectos de los contratos de aprovechamiento por turno de bienes de uso turístico, de adquisición de productos vacacionales de larga duración, de reventa y de intercambio, en su artículo 14. DOUE núm. 33, de 3 de febrero de 2009.

${ }^{48}$ En virtud de la Directiva (UE) 2015/2366 del Parlamento Europeo y del Consejo de 25 de noviembre de 2015 sobre servicios de pago en el mercado interior y por la que se modifican las Directivas 2002/65/CE, 2009/110/CE y 2013/36/UE y el Reglamento (UE) n. ${ }^{\circ}$ 1093/2010. DOUE núm. 337, de 23 de diciembre de 2015.

${ }^{49}$ La Ley de Conciliación en el Sector de la Aviación de 2013 (Gesetz zur Schlichtung im Luftverkehr) crea SOP Ver en: https://soep-online.de/en/, visitado el día 6 de diciembre de 2020.

${ }^{50}$ No obstante, está previsto que la EASA actúe como entidad ADR con resoluciones vinculantes en el ámbito aéreo comercial en virtud de la reciente Disposición final tercera de la Ley 3/2020, de 18 de septiembre, de medidas procesales y organizativas para hacer frente al COVID-19 en el ámbito de la Administración de Justicia, que modifica la Ley 21/2003, de 7 de julio, de Seguridad Aérea en sus artículos 45 bis y 62 bis. Aunque todavía no se ha puesto en marcha. BOE núm. 250, de 19 de septiembre de 2020 .
} 
resolución de litigios ha sido la Directiva 2013/11/UE que citábamos supra. En ella, se establece como obligación para todos los comerciantes, que estén sitos en la Unión Europea, informen a los consumidores acerca de la entidad o entidades de resolución alternativa que den cobertura a dichos comerciantes. Todo ello, sin diferenciar si estos están sometidos de manera voluntaria o legalmente obligados a recurrir a dichas entidades para resolver litigios con los consumidores. Además, la norma no se queda ahí, sino que también obliga a que dicha información incluya la dirección del sitio web de la entidad o entidades de resolución alternativa pertinentes.

30. En este punto, se establece un importante punto de inflexión, donde el legislador, no solo se preocupa de que los comerciantes se adhieran a este tipo de entidades, sino que el consumidor conozca esta circunstancia. Ya que, en muchas ocasiones, aun estando el comerciante sometido a una entidad ADR bien voluntariamente, bien porque así se lo exija el sector o el código de conducta al que esté adherido, o bien porque así se lo exija la legislación, los consumidores, a la hora de realizar una reclamación con el comerciante, en la mayoría de los casos desconocía totalmente la existencia de esta herramienta para solventar el conflicto si no fuese porque el propio comerciante le ofreciese tal vía. Es decir, es prácticamente imposible conocer a qué entidad ADR está adherida la empresa contra la que se reclama, debido al gran volumen de entidades ADR disponibles que operan a nivel internacional.

31. Tanto es así, que solo en la plataforma ODR creada por la Comisión Europea en febrero de 2015 existen 466 entidades acreditadas ${ }^{51}$ por los países miembros para resolver conflictos entre comerciantes y consumidores sitos en el mercado único. Por ello el legislador puso el acento en poner a disposición del consumidor la información sobre la entidad a la que está adherido el comerciante, así como que esta información deberá aparecer de manera clara, comprensible y fácilmente accesible en el sitio web del comerciante, si lo hubiere, y, si procede, en las condiciones generales aplicables a los contratos de compraventa o de servicios entre el comerciante y el consumidor.

32. Posiblemente este sea el apartado que más quebraderos de cabeza está dando al TJUE, ya que no está claramente redactado y tampoco es demasiado concluyente. Sin embargo, el TJUE se ha posicionado protegiendo de los derechos de los consumidores en la STJUE Bundesverband der Verbraucherzentralen und Verbraucherverbände-Verbraucherzentrale Bundesverband eV y Deutsche Apotheker-und Ärztebank e $G^{52}$.

33. Así las cosas, el motivo pivotante del conflicto fue las malas o erróneas prácticas llevadas a cabo por la entidad financiera en materia de comunicación a los consumidores, concretamente respecto de la información sobre la posibilidad de acceder a la resolución alternativa de litigios ante sus reclamaciones. Esta cuestión radica en que a pesar de que el banco cooperativo, ofreció la información referente a la entidad de mediación en consumo a la que está vinculado para la resolución de conflictos en su sitio web, no incluyó dicha información en las condiciones generales de los contratos que el comerciante utiliza. Esto pudo ser comprobado a través de la descarga de las condiciones generales de los contratos que el banco celebraba con sus consumidores disponibles en la propia web del banco en formato PDF.

No obstante, tal y como se establece en la sentencia, tras la celebración de un contrato junto con las condiciones generales controvertidas, el consumidor estaría recibiendo un documento anexo con las condiciones tarifarias establecidas por el banco y al dorso de estas se estaría informando al consumidor de que el banco se compromete a someterse a un procedimiento de resolución de litigios. Sin embargo, la Federación demandante consideró que el lugar donde se facilitaba esta información no era el apro-

\footnotetext{
${ }^{51}$ Por cumplir con los requisitos y los estándares de calidad establecidos en los artículos 6-12 de la Directiva 2013/11. En virtud de las transposiciones a las legislaciones nacionales de la citada Directiva, aunque los Estados han podido aumentar los requisitos y los estándares mínimos establecidos por aquella. La cifra de 466 entidades fue revisada a día 7 de diciembre de 2020, antes de la salida de las entidades radicadas en Reino Unido. Disponible en: https://ec.europa.eu/consumers/odr/ main/?event=main.adr.show2, visitada el 7 de diciembre de 2020.

52 Es importante indicar que en este caso no se han presentado conclusiones del Abogado General, posiblemente debido a la claridad en la letra de la Directiva 2013/11 y por ello este haya declinado aportar conclusiones al asunto.
} 
piado, ni el legalmente establecido para ello. Por ello inició una acción de cesación en su práctica de no indicar en las condiciones generales controvertidas que se compromete o está obligada a someterse a un procedimiento de resolución de litigios ante una entidad de mediación en materia de consumo.

En primera instancia se desestimó el recurso por entender que esta información será exigible al comerciante siempre que este utilice condiciones generales en sus contratos. Sin embargo, el mero hecho de tener públicamente disponibles las condiciones generales de sus contratos en su sitio web no equivale a que este las utilice. Todo ello, además de entender que el hecho de entregar al consumidor en el momento de celebrar el contrato la información objeto del debate, cumple con la legislación alemana que transpone la Directiva 2013/11. A pesar de que la legislación alemana establece que la controvertida información debe facilitarse al consumidor "junto con" las condiciones generales utilizadas por el comerciante, transponiendo el artículo 13 de la Directiva 2013/11 que establece que tal información debe figurar, "en" las condiciones generales si estas estuviesen presentes en el contrato.

Sin embargo, en segunda instancia, tras la apelación por parte del demandante, el Tribunal Superior Regional de lo Civil y Penal de Düsseldorf decidió remitir una cuestión prejudicial al TSJUE.

En definitiva se plantea si era suficiente con que el comerciante presente la información en otros documentos accesibles en el sitio web o en otros documentos anexos al documento principal donde se reflejan las condiciones generales del contrato en el momento de la celebración del mismo, o si por el contrario, el comerciante está obligado a hacer constar en esas condiciones generales la información relativa a la entidad o entidades de ADR que den cobertura a dicho comerciante, cuando este se comprometa a acudir a tales entidades o esté obligado a acudir a ellas.

34. El TJUE se centró en la interpretación del tan comentado artículo 13 de la Directiva 2013/11 además de su relación con el espíritu de la norma. Por ello se dedicó a analizar en primer lugar los considerandos de la Directiva, para no interpretar solo un artículo independientemente de la norma, sino teniendo en cuenta su contexto y los objetivos perseguidos ${ }^{53}$. Así, profundiza en la voluntad de los Considerandos 1, 2, 5, 7 y 47 de la norma, donde se desprende que el objetivo prioritario de esta es lograr un alto nivel de protección del consumidor, garantizando que los consumidores puedan, si lo desean, presentar reclamaciones contra los comerciantes ante entidades que ofrezcan procedimientos de resolución alternativa de litigios. Así mismo, se desprende que para hacer uso de estos mecanismos ADR, los consumidores deberán estar informados, para que cuando surja un conflicto, los consumidores puedan identificar rápidamente qué entidades de resolución alternativa son competentes para tratar su reclamación y saber si el comerciante afectado participará o no en el procedimiento sometido a una entidad de resolución alternativa.

35. Tal y como hemos venido argumentando, en este caso el banco cumplía con el $50 \%$ de la obligación que impone el artículo 13.2 de la Directiva 2013/11 al figurar esta información controvertida en el sitio web del banco. En este caso, se puntualiza por el TJUE que esta obligación es independiente de si este celebra contratos con sus consumidores a través del sitio web o no, cuestión que se plantea en el escrito del Tribunal remitente. La obligación de establecer esta información en el sitio web resulta desde el momento en el que el comerciante tenga sitio web oficial.

36. La cuestión controvertida en este caso la plantea la expresión del citado artículo "y, si procede en las condiciones generales aplicables a los contratos de compraventa o de servicios entre el comerciante y el consumidor". Argumento que el TJUE establece como sumatorio al de que la información esté disponible en el sitio web del comerciante. Y en este punto, la STJUE en su pronunciamiento 30 es

${ }^{53}$ El TJUE en su amplia jurisprudencia ha tenido en cuenta para la interpretación de una disposición del Derecho de la Unión, no solo el tenor de esta, sino también su contexto y los objetivos perseguidos por la legislación de la que forma parte. Ejemplo de ello son las STJUE 15 de octubre de 2014, Hoštická y otros, C-561/13, EU:C:2014:2287, apartado 29 y jurisprudencia citada, la STJUE 19 de septiembre de 2018, González Castro, C-41/17, EU:C:2018:736, apartado 39 y jurisprudencia citada. Además de incidir en la STJUE 8 de mayo de 2019, Inspecteur van de Belastingdienst, C-631/17, EU:C:2019:381, apartado 29 y jurisprudencia que la génesis de una disposición del Derecho de la Unión también puede ofrecer elementos pertinentes para su interpretación como ocurrió con la STJUE 3 de octubre de 2013, Inuit Tapiriit Kanatami y otros/Parlamento y Consejo, C-583/11 P, EU:C:2013:625, apartado 50 y jurisprudencia citada. 
muy clara al indicar que la obligación de información que dicha disposición establece no se cumple si el comerciante que muestra las condiciones generales en su sitio web no hace constar en ellas la referida información, sino que la presenta en otro lugar en dicho sitio, por lo que condenó al banco a incluir esta información dentro de las condiciones generales de sus contratos.

37. Aunque el Tribunal remitente se centró en la solicitud en la interpretación del artículo 13 de la Directiva 2013/11 anteriormente comentado. Sin mencionar ninguna otra norma más. El TJUE, en un alarde de amplio conocimiento de la normativa europea, le refresca la memoria al Tribunal remitente referenciando la Directiva 2011/83 del Parlamento Europeo y del Consejo, de 25 de octubre de 2011, sobre los derechos de los consumidores, por la que se modifican la Directiva 93/13/CEE del Consejo y la Directiva 1999/44/CE del Parlamento Europeo y del Consejo y se derogan la Directiva 85/577/CEE del Consejo y la Directiva 97/7/CE del Parlamento Europeo y del Consejo ${ }^{54}$. Concretamente el TJUE hace referencia al artículo 6 apartado 1, letra t), de la citada Directiva donde se establece que "antes" de que el consumidor quede vinculado por cualquier contrato a distancia o celebrado fuera del establecimiento o cualquier oferta correspondiente, debe ser informado de la posibilidad de recurrir a un mecanismo no judicial de reclamación y recurso al que esté sujeto el comerciante y los métodos para tener acceso al mismo. De este modo, el consumidor podrá decidir si desea vincularse con el comerciante y sitúa a esta información como necesaria para la ejecución del contrato y sobre todo para realizar un ejercicio efectivo de sus derechos, tal y como analizábamos en el apartado sobre la información precontractual.

38. Quizá en este punto podamos advertir cierta incongruencia por extra-petitum del TJUE, ya que en ningún momento se le pregunta por la información precontractual, ni tampoco se le informa de si este tipo de contratos son ofertados por la entidad para realizarlos a distancia. A pesar de que queda claro que el banco no da la posibilidad de realizarlo de forma online desde la web, pero hay silencio en cuanto a si era posible contratar a distancia con el banco.

39. Si bien es cierto que el Tribunal se apoya para extender la cuestión planteada, en que esta información no solo debe ser obligatoria en el momento de la firma del contrato, sino que también es obligada ofrecerla en la etapa precontractual. De este modo se ha dispuesto en cuestiones anteriormente planteadas ante el TJUE con un cariz similar al asunto planteado, sobre todo desde el sector bancario o en el comercio online ${ }^{55}$. Así las cosas, el TJUE sienta que no basta con que dicho comerciante presente esa información en otros documentos accesibles en el referido sitio, en otros desplegables de este o facilite al consumidor tal información en el momento de la celebración del contrato sujeto a las referidas condiciones generales a través de un documento distinto de estas.

\section{Conclusiones}

40. El TJUE una vez más se posiciona como uno de los máximos garantes de los derechos de los consumidores a través de una interpretación extensiva de la norma en sentido pro-consumidor. De esta manera, el Alto Tribunal pretende reequilibrar las fuerzas en la balanza consumidores vs comerciantes. Incluso es acertado concluir que el TJUE garantiza y blinda los derechos de los consumidores más de lo que lo hacen los propios Estados miembros, en sus transposiciones, en la mayoría de las ocasiones descafeinadas, de la normativa europea.

41. En clave nacional, debemos destacar nuestra la claridad normativa a través de la Ley 7/2017, de 2 de noviembre, por la que se incorpora al ordenamiento jurídico español la Directiva 2013/11/UE,

\footnotetext{
${ }^{54}$ DOUE núm. 304, de 22 de noviembre de 2011.

${ }^{55}$ Ejemplo de ello son la STJUE 18 de diciembre de 2014, CA Consumer Finance, C-449/13, EU:C:2014:2464, apartado 46, la STJUE sentencia de 10 de julio de 2019, Amazon EU, C-649/17, EU:C:2019:576, apartado 43 y jurisprudencia citada y la STJUE 23 de enero de 2019, Walbusch Walter Busch, C-430/17, EU:C:2019:47.
} 
del Parlamento Europeo y del Consejo, de 21 de mayo de 2013, relativa a la resolución alternativa de litigios en materia de consumo ${ }^{56}$. Si bien es cierto que fuimos uno de los países que más tardó en transponer la citada Directiva, pero sobre el particular que aquí nos ocupa podemos presumir de amplia claridad ya que los artículos 40 y 41 sobre la obligación de información de los empresarios sobre las entidades acreditadas y el régimen sancionador sobre el incumplimiento de la obligación de información de los empresarios son muy completos y pormenorizados. No obstante, nos surge la duda de si realmente está siendo cumplida por la totalidad de los comerciantes.

${ }^{56}$ BOE núm. 268, de 4 de noviembre de 2017 